Published in final edited form as:

Inorg Chem. 2016 January 19; 55(2): 785-793. doi:10.1021/acs.inorgchem.5b02252.

\title{
Large Ligand Folding Distortion in an Oxomolybdenum Donor- Acceptor Complex
}

\author{
Jing Yang ${ }^{1}$, Benjamin Mogesa ${ }^{2}$, Partha Basu ${ }^{2, *}$, and Martin L. Kirk ${ }^{1,{ }^{*}}$ \\ ${ }^{1}$ Department of Chemistry and Chemical Biology, The University of New Mexico, MSC03 2060, 1 \\ University of New Mexico, Albuquerque, NM 87131-0001 \\ ${ }^{2}$ Department of Chemistry and Biochemistry, Duquesne University, Pittsburgh, PA 15282
}

\begin{abstract}
Interligand charge transfer is examined in the novel metallo-dithiolene complex $\mathrm{MoO}(\mathrm{SPh})_{2}\left({ }^{\mathrm{i}} \mathrm{Pr}_{2} \mathrm{Dt}^{\mathrm{O}}\right)$ (where ${ }^{\mathrm{i}} \mathrm{Pr}_{2} \mathrm{Dt}^{\mathrm{O}}$ is $\mathrm{N}, \mathrm{N}^{\prime}$-isopropyl-piperazine-2,3-dithione). The title complex displays a remarkable $70^{\circ}$ "envelope" type fold of the five member dithiolene ring, which is bent upward toward the terminal oxo ligand. A combination of electronic absorption and resonance Raman spectroscopies have been used to probe the basic electronic structure responsible for the large fold-angle distortion. The intense charge transfer transition observed at $\sim 18,000 \mathrm{~cm}^{-1}$ is assigned as a thiolate $\rightarrow$ dithione ligand-to-ligand charge transfer (LL'CT) transition that also possesses Mo(IV) $\rightarrow$ dithione charge transfer character. Strong orbital mixing between occupied and virtual orbitals with $\mathrm{Mo}\left(\mathrm{x}^{2}-\mathrm{y}^{2}\right)$ orbital character derives from a strong pseudo Jahn-Teller effect, which drives the large fold angle distortion to yield a double well potential in the electronic ground state.
\end{abstract}

\section{SYNOPSIS TOC}

Interligand charge transfer is observed in the novel metallo-dithiolene complex $\mathrm{MoO}(\mathrm{SPh})_{2}\left(\mathrm{Pr}_{2} \mathrm{Dt}^{\mathrm{o}}\right)$ (where ${ }^{\mathrm{i}} \mathrm{Pr}_{2} \mathrm{Dt}_{0}$ is $\mathrm{N}, \mathrm{N}^{\prime}$-isopropyl-piperazine-2,3-dithione). This complex possesses an extremely large $70^{\circ}$ "envelope" type fold of the five member dithiolene chelate ring. Electronic absorption and resonance Raman spectroscopies, coupled with detailed bonding calculations, reveal the electronic origin of the large fold-angle distortion derives from $\left[(\mathrm{SPh})_{2} \mathrm{MoO}\right] \rightarrow$ dithione back donation, which has its origins in a strong pseudo Jahn-Teller distortion that warps the ground state potential energy surface.

*Corresponding Author: Martin L. Kirk (; Email: mkirk@unm.edu); Partha Basu (; Email: basu@duq.edu)

Supporting Information. Summary of crystallographic data, Table of Cambridge crystallographic database ligand fold angles, relevant molecular orbitals, $488 \mathrm{~nm}$ Raman spectrum of $\mathrm{MoO}(\mathrm{SPh})_{2}\left({ }^{\mathrm{i}} \mathrm{Pr}_{2} \mathrm{Dt}^{\mathrm{O}}\right)$, and a graphical description of relevant normal modes. This material is available free of charge via the Internet at http://pubs.acs.org. 


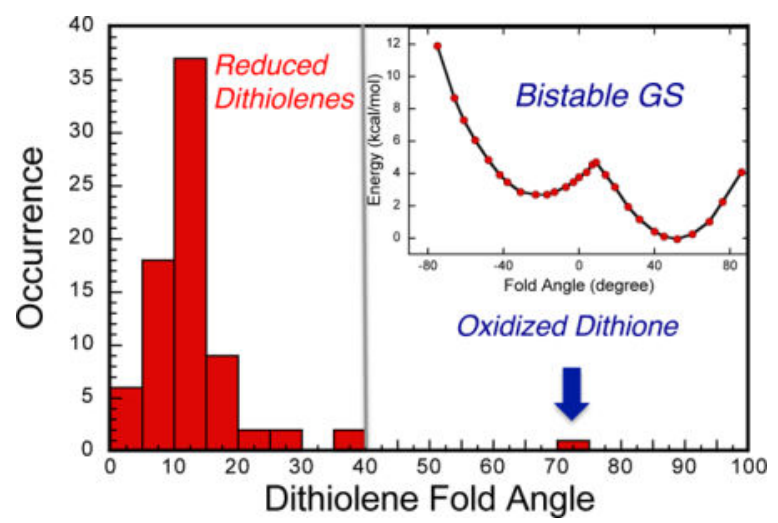

\section{Keywords}

Molybdenum; Dithiolene; Jahn-Teller; Dithione; Charge Transfer; Raman; Electronic Structure

\section{INTRODUCTION}

Mixed-ligand transition metal complexes containing both electron rich (donor) and electron poor (acceptor) ligands can give rise to interesting and complex electronic structures. The resulting asymmetric charge distribution in the electronic ground state of these complexes can lead to interesting charge transfer behavior, most notably the occurrence of low energy ligand-to-ligand charge transfer (LL'CT) excitations that dramatically redistribute the charge density in excited states relative to the ground state. Dithiolene ligands have been extensively used as donor ligands in the synthesis of complexes that possess LL'CT and mixed-metal LL'CT (MMLL'CT) transitions. ${ }^{1{ }^{1} 7}$ These generalized Donor-Acceptor LL'CT complexes display interesting photophysical processes related to the formation of charge separated excited states that formally possess dithiolene radical (i.e. hole) and acceptor ligand radical (i.e. electron) character. These properties include long-lived photoluminescence lifetimes, highly tunable emission energies, oxidative and reductive electron transfer quenching, and photooxidation chemistry. ${ }^{1,8}$ Square planar mixed-ligand dithiolene complexes possess LL'CT transitions that are often quite intense (large transition dipole moment) due to good overlap of the donor (D) and acceptor (A) ligands, and these LL 'CT absorptions often occur at low transition energies that extend into the near-infrared (NIR) region of the optical spectrum.

Scheme 1 depicts the various dithiolene ligand forms that may be encountered in noninnocent complexes with transition metal ions. The dianionic ene-1,2-dithiolate is a good $\sigma$ and $\pi$-donor ligand that forms very covalent metal-ligand bonds. ${ }^{9}$ In fact, the high degree of metal-dithiolene covalency, coupled with the extended $\pi$-system of the dithiolene ligand, contributes greatly to the observed non-innocent behavior in transition metal complexes that incorporate this ligand ${ }^{10} 12$. Oxidized radical ion forms of the dithiolene have been observed in complexes that possess multiple dithiolene ligands, ${ }^{11}{ }^{13}$ with electron delocalization (i.e. ligand mixed-valency) contributing to the stabilization of this form of the ligand. ${ }^{9}$ Rarer still are complexes that employ the two-electron oxidized 1,2-dithione form of the ligand, ${ }^{9}$ which possesses $\pi$-acceptor character and is expected to stabilize lower valent transition metal ion 
complexes. ${ }^{14 \_17}$ As a result of this rarity, there exists a dearth of geometric and electronic structure studies on metallo-monodithiolene complexes that possess the fully oxidized form of the dithiolene ligand.

In this manuscript, we investigate a novel donor-acceptor type Mo-dithiolene complex, $\mathrm{MoO}(\mathrm{SPh})_{2}\left({ }^{i} \mathrm{Pr}_{2} \mathrm{Dt}^{\mathrm{O}}\right)$ (Figure 1), where the dithiolene ligand is in the oxidized dithione form and is intimately associated with a piperazine ring. ${ }^{18},{ }^{19}$ Specifically, we detail the synthesis, $\mathrm{X}$-ray structure, and spectroscopy of this complex, and relate an unprecedented dithiolene ligand folding distortion to its unique electronic structure. We find that the large dithione ligand folding in this complex derives from a vibronically induced distortion that results in increased covalency in the folded geometry, and this allows for in-plane occupied orbitals associated with the $\left[(\mathrm{SPh})_{2} \mathrm{MoO}\right]$ fragment of the molecule to donate electron density into an out-of-plane unoccupied orbital localized on the $\left({ }^{i} \mathrm{Pr}_{2} \mathrm{Dt}^{\mathrm{O}}\right)$ acceptor ligand fragment.

\section{EXPERIMENTAL}

\section{Materials}

The chemicals were purchased from Aldrich Chemical Company or ACROS Chemical Company and were used without further purification. Commercial grade solvents were dried and purified using a solvent purification system (SP-105) by LC Technology Solutions Inc. before use. Chloroform was dried and distilled over $\mathrm{CaH}_{2}$. NMR spectra were collected on Bruker Avance 400, or 500 spectrometers. IR spectra were recorded either on a PerkinElmer FT-IR 1760X spectrometer or a Nicolet 380 FT-IR (Thermo) spectrometer. Elemental analysis was performed at Midwest Microlab LLC., Indiana, IL. N, $\mathrm{N}^{\prime}$-diisopropyl piperazine 2,3-dithione $\left({ }^{i} \mathrm{Pr}_{2} \mathrm{Dt}^{\mathrm{o}}\right)$ and $\left[\mathrm{MoOCl}\left({ }^{i} \mathrm{Pr}_{2} \mathrm{Dt}^{\mathrm{o}}\right)_{2}\right]\left[\mathrm{PF}_{6}\right]$ were synthesized according to literature procedures. $^{20}$

\section{Synthesis of $\mathrm{MoO}(\mathrm{SPh})_{2}\left({ }^{i} \mathrm{Pr}_{2} \mathrm{Dt}^{\circ}\right)(1)$}

The mixed ligand complex, $\mathrm{MoO}(\mathrm{SPh})_{2}\left(\mathrm{Pr}_{2} \mathrm{Dt}^{\mathrm{o}}\right)$ was synthesized via ligand exchange reaction from the starting material $\left[\mathrm{MoOCl}\left({ }^{i} \mathrm{Pr}_{2} \mathrm{Dt}^{\mathrm{O}}\right)_{2}\right]\left[\mathrm{PF}_{6}\right]$. To an acetonitrile solution (60 $\mathrm{mL})$ of $0.2 \mathrm{~g}(0.26 \mathrm{mmol})$ of $\left[\mathrm{MoOCl}\left({ }^{i} \mathrm{Pr}_{2} \mathrm{Dt}^{\circ}\right)_{2}\right]\left[\mathrm{PF}_{6}\right]$, two equivalents of an equimolar solution of benzenethiol and triethylamine in $3 \mathrm{~mL}$ acetonitrile were added, turning the blue solution purple. After one hour, the solution was dried in vacuum, and the crude product was dissolved in a minimum amount of chloroform and filtered to remove solid materials, if any. The filtrate was layered with ether and kept in cold $\left(\sim 4^{\circ} \mathrm{C}\right)$ overnight. The target compound was recrystallized from acetonitrile-ether solution and the X-ray quality single crystals were filtered and the volume of the filtrate was reduced and layered with ether again to obtain an additional crop of crystals. Collected crystals weigh $0.056 \mathrm{~g}$ (Yield: $37 \%$ ). The complex is readily soluble in acetonitrile and sparingly soluble in dichloromethane or chloroform.

Anal. calcd. (experimental) for $\mathrm{C}_{22} \mathrm{H}_{28} \mathrm{~N}_{2} \mathrm{~S}_{4} \mathrm{MoO}$ : C, 47.13 (47.06); $\mathrm{H}, 4.94$ (5.03); $\mathrm{N}, 4.91$ (5.00). ${ }^{1} \mathrm{H}$ NMR $\left(\mathrm{CD}_{3} \mathrm{CN}\right): \delta=7.55(\mathrm{~d}, \mathrm{Ph}, 2 \mathrm{H}) ; 7.26(\mathrm{t}, \mathrm{Ph}, 4 \mathrm{H}) ; 7.16(\mathrm{t}, \mathrm{Ph}, 4 \mathrm{H}), 4.73(\mathrm{~m}$, $\mathrm{CH}, 2 \mathrm{H}) ; 3.91\left(\mathrm{~m}, \mathrm{CH}_{2}, 2 \mathrm{H}\right) ; 3.61\left(\mathrm{~m}, \mathrm{CH}_{2}, 2 \mathrm{H}\right) ; 1.30\left(\mathrm{~d}, \mathrm{CH}_{3}, 6 \mathrm{H}\right) ; 1.16\left(\mathrm{~d}, \mathrm{CH}_{3}, 6 \mathrm{H}\right) .{ }^{13} \mathrm{C}$ $\operatorname{NMR}\left(\mathrm{CDCl}_{3}\right): \delta=19.02\left(\mathrm{CH}_{3}\right), 20.21\left(\mathrm{CH}_{2}\right), 41.81(\mathrm{CH}), 125.43,127.66,134.34(\mathrm{Ph})$, 
$148.05(\mathrm{C}=\mathrm{S})$. IR (neat) $\mathrm{cm}^{-1}: 1568$ (vs, $\left.(\mathrm{C}=\mathrm{S})-\mathrm{N}\right), 1470$ (vs, $\left.\mathrm{C}=\mathrm{S}\right), 939$ (vs, $\left.\mathrm{Mo}=\mathrm{O}\right) . \lambda_{\max }$,

$\mathrm{nm}\left(\varepsilon, \mathrm{M}^{-1} \mathrm{~cm}^{-1}\right)$ in $\mathrm{CH}_{3} \mathrm{CN}: 540$ (7,065), 344 (sh, 9,828), 300 (sh, 13,400), 250 (26,100).

\section{X-ray Structure Determination}

$\mathrm{X}$-ray quality single crystals of $\mathrm{MoO}(\mathrm{SPh})_{2}\left(\mathrm{Pr}_{2} \mathrm{Dt}^{\mathrm{o}}\right)$ were obtained by slow diffusion of ether into acetonitrile-ether solutions of the complex. A single crystal was mounted on a glass fiber and intensities recorded on a Bruker SMART Apex II diffractometer with a graphite monochromator for Mo- $\mathrm{K}_{\mathrm{a}}$ radiation $(\lambda=0.71703 \AA$ ). A total of 11144 reflections were collected at $150 \mathrm{~K}$, of those 5657 reflections were independent and 3936 reflections satisfied the condition $\mathrm{I}>2 \sigma(\mathrm{I})$, and were used for structure determination. A twining law was applied for data reduction. ${ }^{21}$ Absorption correction was performed using the SADABS. Based on the systematic absences XPREP determined space group, the structure was solved with the space group R-3 (rhombohedral crystal system). The structure was solved using the Direct method incorporated in SHELX-97. The structure was refined using full matrix least square method. All non-hydrogen atoms were refined anisotropically while hydrogen atoms were added using the riding model. A total of 3936 reflections were used for refine 276 parameters. The structure was refined to $\mathrm{R}=0.082$ with GOF 1.43 . Details of the structure determination are listed in Supporting Information, Table S1.

\section{Electronic Absorption Spectroscopy}

Electronic absorption spectra were collected on a double-beam Hitachi U-4100 UV-vis-NIR spectrophotometer capable of scanning a wavelength region between 185 and $3300 \mathrm{~nm}$.

Room temperature solution spectra were collected in acetonitrile and butyronitrile using a 1 $\mathrm{cm}$ path length, black-masked, quartz cuvette (Starna Cells, Inc.) equipped with a Teflon stopper. The instrument was calibrated with reference to an internal $656.1 \mathrm{~nm}$ deuterium line using the native Hitachi software.

\section{Resonance Raman Spectroscopy}

Samples for the resonance Raman spectroscopy were prepared by diluting them in a solid state matrix consisting of finely ground $\mathrm{NaCl} / \mathrm{Na}_{2} \mathrm{SO}_{4}$ in an approximate $10: 1$ ratio by weight. The combined compound and matrix mix were then ground together again to achieve a uniform sample. These samples were then put into quartz capillary tubes, which were subsequently flame-sealed and placed in a sample spinner assembly to minimize thermal and photochemical degradation. Raman shifts were calibrated against the $992 \mathrm{~cm}^{-1}$ band of the $\mathrm{SO}_{4}{ }^{2-}$ internal standard. Data were collected using a $90^{\circ}$ scattering geometry. The Raman scattered light was focused onto the entrance slit of a PI/Acton Spectrapro SP-2500i $500 \mathrm{~mm}$ focal length spectrograph with a triple-grating turret monochromator. A liquid-nitrogen cooled detector, PI/Acton Spec-10:100B back-illuminated 1340_100 pixel digit CCD camera, was used in all experiments. Coherent Innova $\mathrm{Ar}^{+}$and $\mathrm{Kr}^{+}$lasers were used as excitation sources. The laser output was directed through Semrock Maxline laser line filters in order to remove plasma lines, and Semrock Razor Edge long pass filters were utilized to eliminate dominant contributions from the Rayleigh line. Laser power was measured at the sample. In order to avoid photobleaching or thermal degradation of the sample, low laser powers $(\sim 15 \mathrm{~mW}$ for $407 \mathrm{~nm}, \sim 20 \mathrm{~mW}$ for $458 \mathrm{~nm}$ and $488 \mathrm{~nm}, \sim 25 \mathrm{~mW}$ 
for $514 \mathrm{~nm}, \sim 35 \mathrm{~mW}$ for $568 \mathrm{~nm}, \sim 50 \mathrm{~mW}$ for $647 \mathrm{~nm}$ ) were utilized in combination short exposure times.

\section{Computational Details}

Spin-restricted gas phase geometry optimizations and TDDFT calculations were performed at the density functional theory (DFT) level using Gaussian $03 \mathrm{~W}^{22}$. Full geometry optimizations were performed in $C_{1}$ and $C_{S}$ symmetry with qualitatively similar results. All Gaussian 03W calculations used the B3LYP hybrid exchange-correlation functional. A 6-31G* basis set was used for all atoms except for molybdenum, where a LANL2DZ basis set was used in combination with an effective core potential. Fragment molecular orbital analyses were performed using the program AOMix. ${ }^{23}$

\section{RESULTS and DISCUSSION}

\section{X-Ray Structure}

The molecular structure of $\mathrm{MoO}(\mathrm{SPh})_{2}\left(\mathrm{Pr}_{2} \mathrm{Dt}^{\mathrm{o}}\right)$ has been determined by single crystal diffractometry (Figure 1). A summary of crystallographic data and selected metric parameters are listed in the SI (Tables S1 and S2). The oxomolybdenum center adopts a square pyramidal geometry coordinated by four sulfur donors. Two sulfur donors derived from the $\mathrm{N}^{\prime} \mathrm{N}$-isopropyl-piperazine-2,3-dithione ligand and two thiophenolato sulfur donors complete the first coordination sphere. The molybdenum atom lies $0.8 \AA$ above the $\mathrm{S}_{4}$ plane. The Mo $\equiv \mathrm{O}$ distance of 1.682 (2) $\AA$ is consistent with $\mathrm{Mo} \equiv \mathrm{O}$ distances found in other complexes. The Mo S distances range from 2.381 to $2.415 \AA$ indicating that there are no significant differences between the two types of sulfur donors ( $c$ a. thiolato and thione). The observed Mo-S distances are within the range of Mo-S (thiol) ${ }^{24,25}$ and Mo-S (thione) ${ }^{17,26}$ distances reported in the literature. ${ }^{27,28}$ The $\mathrm{C}=\mathrm{S}$ (thione) distances are $0.06 \AA$ shorter than $\mathrm{C}-\mathrm{S}$ (thiol) bond lengths in $\mathrm{MoO}(\mathrm{SPh})_{2}{ }^{\mathrm{i}} \mathrm{Pr}_{2} \mathrm{Dt}^{\mathrm{o}}$. Additionally, there are two types of $\mathrm{C}-\mathrm{N}$ distances observed in this structure. The $\mathrm{C}(=\mathrm{S})-\mathrm{N}$ distances are shorter than the $\mathrm{C}\left(-\mathrm{C}_{\text {ring }}\right)-\mathrm{N}$ distances by $\sim 0.13 \AA$. The most striking feature of the structure is remarkably large folding of the dithione ligand away from the $\mathrm{S}_{4}$ plane towards the terminal oxo donor. The fold angle $(\eta)$ is defined as the angle between the planes created by molybdenum and two sulfur atoms from dithione ligand and the plane created by the $\mathrm{S}=\mathrm{CC}=\mathrm{S}$ dithione fragment. This large fold angle of $\sim 70^{\circ}$ is unique among all the structurally characterized oxomolybdenum dithiolene complexes (Figure 2). The consequence of this rare geometric feature on the electronic structure is enormous and results in low-energy charge transfer features that uncommon for a Mo(IV) complex with a low-spin $\mathrm{d}^{2}$ electron configuration.

\section{Bonding Interactions}

The terminal oxo donor dominates the ligand field of monoxomolybdenum complexes, and this leads to a large destabilization of the $\operatorname{Mo}\left(4 \mathrm{dz}^{2}\right)$ and $\mathrm{Mo}(4 \mathrm{dxz}, 4 \mathrm{dyz})$ orbitals due to strong $\sigma$ and $\pi$ bonding interactions within the $\mathrm{Mo} \equiv \mathrm{O}$ unit. Additionally, the $\mathrm{Mo}(\mathrm{dxy})$ orbital possesses a $\sigma^{*}$ interaction with the equatorial ligand set and is also significantly destabilized to yield an $\left(\mathrm{x}^{2}-\mathrm{y}^{2}\right)^{2}(\mathrm{xz}, \mathrm{yz})^{0}(\mathrm{xy})^{0}\left(\mathrm{z}^{2}\right)^{0}$ electron configuration for $\mathrm{d}^{2} \mathrm{Mo}(\mathrm{IV})$. This results in high energy ligand-to-metal charge transfer (LMCT) transitions to virtual Mo states due to the large destabilization of the four metal-ligand antibonding orbitals primarily 
localized on Mo and the fact that the $\left(\mathrm{x}^{2}-\mathrm{y}^{2}\right)$ orbital is doubly occupied. Thus, the lowest LMCT transitions will be to the unoccupied (dxz,yz) orbitals as they are the most energetically accessible.

Phenylthiolate ligands form very covalent bonds with high-valent oxomolybdenum centers ${ }^{25,29,30}$ and can donate appreciable electron density to vacant Mo orbitals via charge donation from their highest energy filled $S^{\mathrm{v}}$ and $S^{\sigma}$ orbitals.(Figure $\mathrm{S} 1$ ) Here, the $\mathrm{S}^{\mathrm{v}}$ p orbital is oriented in the plane of the phenyl ring and the $S^{\sigma} p$ orbital is orthogonal to the phenyl ring plane. The third $\mathrm{PhS}^{-} \mathrm{S}$ p orbital is involved in S-C $\sigma$ bonding and is therefore unavailable for appreciable Mo-S bonding interactions. In complexes with metal ions the $S^{v}$ and $S^{\sigma}$ orbitals can mix, and this leads to $S^{\mathrm{V}}$ and $S^{\sigma}$ orbital rotation about the S-C bond.

Metallo-dithiolene complexes are known to display a complex redox interplay between the metal and the dithiolene ligand, and this leads to the common description of dithiolenes as non-innocent ligands. ${ }^{31}, 32$ As mentioned above, these ligands can exist in the dianionic dithiolate form, the one-electron oxidized monoanion radical, or in the neutral two-electron oxidized state (Scheme 1). A molecular orbital diagram for the simple dianionic dithiolene $\left[\mathrm{C}_{2} \mathrm{H}_{5} \mathrm{~S}_{2}\right]^{2-}$, depicting the occupied frontier dithiolene ligand orbitals, is given in Figure 3 . $^{9}$ Here, the symmetric and antisymmetric out-of-plane $\left(S_{o p}\right)$ p orbitals are denoted as $\varphi_{o p}{ }^{a}{ }^{\prime}$ and $\varphi_{\mathrm{op}}{ }^{\mathrm{a} \prime \prime}$, and the occupied symmetric and antisymmetric in-plane $\left(\mathrm{S}_{\mathrm{ip}}\right) \mathrm{p}$ orbitals are denoted as $\varphi_{\mathrm{ip}}{ }^{\mathrm{a} \prime}$ and $\varphi_{\mathrm{ip}}{ }^{\mathrm{a} \prime \prime}$ using idealized $C_{s}$ point symmetry. The superscripts a ${ }^{\prime}$ and $\mathrm{a}^{\prime \prime}$ reflect the orbital symmetry with respect to a mirror plane that is oriented perpendicular to the dithiolene ring plane and bisecting both the $\mathrm{S}-\mathrm{S}$ vector and the $\mathrm{C}=\mathrm{C}$ bond. Removal of two electrons from the $\varphi_{\mathrm{ip}}{ }^{\mathrm{a}}$ orbital of the dianionic dithiolene leads to the dithiete resonance form $^{33}$, while removal of two electrons from the $\varphi_{\mathrm{op}}{ }^{\mathrm{a}}$ orbital results in the dithione resonance form (Figure 3 right and Scheme 1). Since the $\varphi_{\text {ip }}{ }^{\text {a }}$ orbital can form $\sigma$ bonds with the metal $\mathrm{d}(\mathrm{xy})$ orbital, removal of two electrons from $\varphi_{\mathrm{ip}}{ }^{\mathrm{a}}$ " results in a ligand that is a very poor donor to the metal. In marked contrast, the removal of two electrons from $\varphi_{\mathrm{op}}{ }^{\mathrm{a} /}$ results in a strong $\pi$-acceptor ligand, and this increases bonding interactions with electron rich oxidizable metals such as $\mathrm{d}^{2} \mathrm{Mo}(\mathrm{IV})$. The highest energy occupied molecular orbital (HOMO) and lowest unoccupied molecular orbital (LUMO) of the ${ }^{i} \mathrm{Pr}_{2} \mathrm{Dt}^{\mathrm{O}}$ ligand are also shown in Figure 3 for comparison with the simple dithiolene $\left(\mathrm{C}_{2} \mathrm{H}_{2} \mathrm{~S}_{2}\right)^{2-}$. Here, the LUMO of the ${ }^{i} \mathrm{Pr}_{2} \mathrm{Dt}^{\mathrm{o}}$ ligand is the $\varphi_{\mathrm{op}}{ }^{\mathrm{a} \prime}$ orbital, indicating that the ${ }^{\mathrm{i}} \mathrm{Pr}_{2} \mathrm{Dt}^{\mathrm{o}}$ ligand in $\mathrm{MoO}(\mathrm{SPh})_{2}\left({ }^{(} \mathrm{Pr}_{2} \mathrm{Dt}^{\mathrm{o}}\right)$ is fully oxidized and in the dithione resonance form. Thus, the ${ }^{i} \mathrm{Pr}_{2} \mathrm{Dt}^{\mathrm{O}}$ ligand is expected to be a $\sigma$-donor, and strong $\pi$-acceptor ligand due to the low-lying empty $\varphi_{\mathrm{op}}{ }^{\mathrm{a} \prime}$ orbital. In combination with the electron rich Mo(IV) center and the strongly electron donating $\mathrm{PhS}^{-}$ligands, this leads to the possibility of low energy $\mathrm{PhS}^{-}(\mathrm{L}) \rightarrow$ dithione $\left(\mathrm{L}^{\prime}\right)$ ligand-to-ligand charge transfer (LL'CT) transitions.

Bonding calculations reveal the valence $\mathrm{MO}$ diagram for $\mathrm{MoO}(\mathrm{SPh})_{2}\left(\mathrm{Pr}_{2} \mathrm{Dt}^{\mathrm{O}}\right)$ depicted in Figure 4. Here, the LUMO is of a $\mathrm{a}^{\prime}$ symmetry (idealized $\left.C_{S}\right)$ and possesses both $\mathrm{Mo}\left(\mathrm{dx}^{2}-\mathrm{y}^{2}\right)$ and ${ }^{i} \mathrm{Pr}_{2} \mathrm{Dt}^{\mathrm{o}} \varphi_{\mathrm{op}}{ }^{\mathrm{a}}$ ligand LUMO character. The HOMO also has a' symmetry and possesses opposite phase contributions from $\mathrm{Mo}\left(\mathrm{dx}^{2}-\mathrm{y}^{2}\right)$ and the ${ }^{\mathrm{i}} \mathrm{Pr}_{2} \mathrm{Dt}^{\mathrm{o}}$ ligand LUMO in addition to an $\mathrm{a}^{\prime}$ symmetry adapted linear combination (SALC) deriving from the $\left(\mathrm{PhS}^{-}\right)_{2}$ ligand set. The HOMO-1 - HOMO-4 orbitals are dominantly $\left(\mathrm{PhS}^{-}\right)_{2}$ ligand based as expected from their electron donating nature. The $\mathrm{a}^{\prime} \mathrm{HOMO}-2$ also possesses some $\mathrm{Mo}\left(\mathrm{x}^{2}-\mathrm{y}^{2}\right)$ orbital 
character. Mo based orbitals lying above the LUMO (not shown) include the $\mathrm{Mo}(\mathrm{xz})$ and $\mathrm{Mo}(\mathrm{yz})$ orbitals that possess extensive $\mathrm{Mo} \equiv \mathrm{O} \pi^{*}$ antibonding character.

The electron acceptor character of the ${ }^{\mathrm{i}} \mathrm{Pr}_{2} \mathrm{Dt}^{\mathrm{o}}$ ligand is more fully revealed in a fragment molecular orbital analysis of $\mathrm{MoO}(\mathrm{SPh})_{2}\left(\mathrm{Pr}_{2} \mathrm{Dt}^{\mathrm{O}}\right)$. In Figure 5, we display the key interactions between the $\left[(\mathrm{SPh})_{2} \mathrm{MoO}\right] \mathrm{a}^{\prime} \mathrm{HOMO}$ donor fragment and the $\mathrm{a}^{\prime} \mathrm{LUMO}$ and HOMO-1 orbitals of the ${ }^{\mathrm{i}} \mathrm{Pr}_{2} \mathrm{Dt}^{\mathrm{O}}$ acceptor. Here, a large F1 HOMO $\rightarrow$ F2 LUMO donoracceptor interaction is readily apparent in the ligand folded geometry that serves to stabilize the $\mathrm{HOMO}$ of the $\mathrm{MoO}(\mathrm{SPh})_{2}\left({ }^{1} \mathrm{Pr}_{2} \mathrm{Dt}^{\circ}\right)$ complex (Figure 5, center). In the absence of any dithione ligand folding, we observe a marked $67 \%$ reduction in the F2 LUMO character present in the HOMO of the complex, indicating a decrease in the acceptor capability of the ${ }^{\mathrm{i}} \mathrm{Pr}_{2} \mathrm{Dt}^{\mathrm{O}}$ ligand at this planer reference geometry.

\section{Spectroscopy and Band Assignments}

The Gaussian resolved room temperature electronic absorption spectrum for $\mathrm{MoO}(\mathrm{SPh})_{2}\left(\mathrm{i}_{2} \mathrm{Dt}^{\circ}\right)$ in acetonitrile is presented in Figure 6. The lowest energy absorption maximum occurs at $\sim 18,200 \mathrm{~cm}^{-1}\left(\varepsilon=7063 \mathrm{M}^{-1} \mathrm{~cm}^{-1}\right)$. This band is distinctly nonGaussian; with a low-energy tail that indicates at least one other excitation contributing at energies lower than $\sim 18,000 \mathrm{~cm}^{-1}$. Higher energy bands are present at $\sim 23,000 \mathrm{~cm}^{-1}$ and at $\sim 29,000 \mathrm{~cm}^{-1}$. The magnitude of the extinction coefficients for these bands strongly supports a charge transfer origin for the observed transitions. Ligand field excitations are difficult to observe in oxo-molybdenum dithiolene complexes due to their inherently low oscillator strengths when compared to even the weakest spin allowed charge transfer bands. Thus we only expect to observe charge transfer transitions in the electronic absorption spectrum. There are four linear combinations of double occupied $\mathrm{PhS}^{-}$frontier donor orbitals, and these derive from the $\mathrm{S}^{\mathrm{v}}$ and $\mathrm{S}^{\sigma}$ orbitals on the two $\mathrm{PhS}^{-}$ligands. Additionally, $\operatorname{Mo}\left(x^{2}-y^{2}\right)$ orbital is doubly occupied. Together, these mix to form the five highest energy occupied orbitals in $\mathrm{MoO}(\mathrm{SPh})_{2}\left(\mathrm{Pr}_{2} \mathrm{Dt}^{\mathrm{O}}\right)$. Thus, we can anticipate five low-energy charge transfer transitions that originate from one-electron promotions involving these filled HOMOs to the ${ }^{i} \mathrm{Pr}_{2} \mathrm{Dt}^{\mathrm{O}}$ LUMO.

We have collected solid state resonance Raman spectra for $\mathrm{MoO}(\mathrm{SPh})_{2}\left({ }^{\mathrm{i}} \mathrm{Pr}_{2} \mathrm{Dt}^{\mathrm{O}}\right)$ and the spectrum collected using $488 \mathrm{~nm}$ excitation is shown in Figure S2. Computationally assisted Raman vibrational assignments are listed in Table 1, and the description of these modes are graphically displayed in Figure S3. Four vibrational bands are clearly observed at frequencies below $\sim 500 \mathrm{~cm}^{-1}\left(v_{25}, v_{31}, v_{35} / v_{36}\right.$, and $\left.v_{37}\right)$. The $v_{25}$ mode is assigned as the $\mathrm{Mo} \equiv \mathrm{O}$ wag, and each of the other low-frequency modes also possess a $\mathrm{Mo} \equiv \mathrm{O}$ wagging component to varying degrees. The $v_{31}$ mode possesses dithione C-S-S-C bending character. The $v_{35} / v_{36}$ modes occur at similar frequencies and possess dithione $\left(v_{35}\right)$ and thiolate $\left(v_{36}\right)$ S-Mo-S stretching character, respectively, in addition to dithione ring folding. The $v_{37}$ mode also possesses a dithione S-Mo-S stretching component, in addition to ring folding and C-N stretching motions. The characteristic $\mathrm{Mo} \equiv \mathrm{O}$ stretch is observed at $945 \mathrm{~cm}^{-1}$.

Resonance Raman excitation profiles have been constructed for these low-frequency vibrational modes in order to make assignments for the individual bands present in the electronic absorption spectrum, and to develop insight into the electronic structure of 


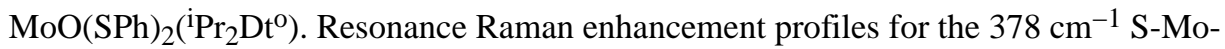
S/Mo-dithione stretching and the $945 \mathrm{~cm}^{-1} \mathrm{Mo} \equiv \mathrm{O}$ stretching modes are shown in Figure 7. The Raman enhancement profiles for the other low frequency modes essentially mirror that of the $378 \mathrm{~cm}^{-1}$ mode. Interestingly, the resonance Raman profiles for these modes display orthogonal resonance enhancement patterns, with the low-frequency Mo-S modes being resonantly enhanced under the $\sim 18,000 \mathrm{~cm}^{-1}$ band and the $\mathrm{Mo} \equiv \mathrm{O}$ stretch being enhanced with optical excitation at higher energies. We have previously used this orthogonal enhancement spectroscopic signature to assign electronic transitions to the $\operatorname{Mo}\left(\mathrm{dx}^{2}-\mathrm{y}^{2}\right)$ and $\mathrm{Mo}(\mathrm{dxz}, \mathrm{yz})$ acceptor orbitals in oxomolybdenum complexes. ${ }^{34,}{ }^{35} \mathrm{In} \mathrm{MoO}(\mathrm{SPh})_{2}\left({ }^{\mathrm{i}} \mathrm{Pr}_{2} \mathrm{Dt}^{\mathrm{O}}\right)$, resonance enhancement of the Mo-dithione S-Mo-S stretching mode is anticipated for transitions from filled thiol and $\mathrm{Mo}\left(\mathrm{dx}^{2}-\mathrm{y}^{2}\right)$ based MOs to the dithione based LUMO, which also possesses in-plane $\mathrm{Mo}\left(\mathrm{dx}^{2}-\mathrm{y}^{2}\right)$ character. Resonance enhancement of the $\mathrm{Mo} \equiv \mathrm{O}$ stretch is anticipated for transitions to the higher energy $\mathrm{Mo}(\mathrm{dxz}, \mathrm{yz})$ virtual orbital set since the $\mathrm{Mo}(\mathrm{dxz}, \mathrm{yz})$ orbitals possess $\mathrm{Mo} \equiv \mathrm{O} \pi^{*}$ character and electron occupation of $\mathrm{Mo} \equiv \mathrm{O} \pi^{*}$ orbitals will result in large excited state distortions along the $\mathrm{Mo} \equiv \mathrm{O}$ bond. In accord with the frontier molecular orbital diagram in Figure 4 the lowest energy charge transfer bands involve one-electron promotions to the $\mathrm{a}^{\prime}$ Modithione acceptor orbital with excited state distortions along dithiolate/dithione modes, while higher energy charge transfer transitions involve one electron promotions to the dxz,yz orbital set with excited state distortions along the $\mathrm{Mo} \equiv \mathrm{O}$ bond. Thus, a combination of electronic absorption and resonance Raman spectroscopic data, coupled with time-dependent DFT (TDDFT), calculations and comparisons to previously assigned spectra for $\mathrm{Tp} * \mathrm{MoO}$ (dithiolene) complexes, ${ }^{31}, 32,35$ _37 allow for a reasonable assignment (Table 2) of the Gaussian resolved optical bands presented in Figure 6. Bands 1-4 are assigned as LL'CT transitions that derive from thiolate $\rightarrow$ dithione one-electron promotions and band 5 is assigned as a $\mathrm{Mo}\left(\mathrm{x}^{2}-\mathrm{y}^{2}\right) \rightarrow$ dithione MLCT transition with appreciable LL'CT character. The resonance profiles allow Bands 6-8 to be assigned as $\mathrm{SPh} \rightarrow \mathrm{Mo} \equiv \mathrm{O} \pi *$ transitions.

Thus, $\mathrm{MoO}(\mathrm{SPh})_{2}\left(\mathrm{Pr}_{2} \mathrm{Dt}^{\mathrm{o}}\right)$ represents a remarkable example of a complex that displays intense LL'CT transitions in the visible region of the spectrum that derive from a high degree of donor-acceptor orbital mixing. The dramatic folding of the dithione ligand is a direct consequence of strong mixing between the $\mathrm{A}^{\prime}$ ground state and low-lying $\mathrm{A}^{\prime}$ LL'CT states with HOMO $\rightarrow$ LUMO and HOMO-1 $\rightarrow$ LUMO CT character. The dithione folding allows for strong orbital overlap between the in-plane $\mathrm{Mo}\left(\mathrm{dx}^{2}-\mathrm{y}^{2}\right)$ orbital and the unoccupied outof-plane $\varphi_{\mathrm{op}}{ }^{\mathrm{a} \prime}$ dithione acceptor orbital, providing a mechanism for a high degree of $\left[(\mathrm{SPh})_{2}\right.$ $-\operatorname{Mo}\left(\mathrm{dx}^{2}-\mathrm{y}^{2}\right) \rightarrow$ dithione charge donation and increased Mo - dithione covalency. Interestingly, the direction of the ligand/Mo $\left(\mathrm{dx}^{2}-\mathrm{y}^{2}\right) \rightarrow$ dithione charge transfer is opposite the dithiolene $\rightarrow \mathrm{Mo}\left(\mathrm{dx}^{2}-\mathrm{y}^{2}\right)$ charge donation observed in higher valent monooxomolybdenum dithiolene complexes where the $\mathrm{Mo}\left(\mathrm{dx}^{2}-\mathrm{y}^{2}\right)$ acceptor orbital is either partially or completely unoccupied. ${ }^{35,36}$ For these higher valent oxomolybdenum dithiolenes, dithiolene $\rightarrow \mathrm{Mo}\left(\mathrm{dx}^{2}-\mathrm{y}^{2}\right)$ LMCT character admixed into the ground state is responsible for dithiolene ligand folding (Figure 2). ${ }^{35,38 \_41}$ 


\section{Vibronic Instability and Increased Covalency}

Approximately $95 \%$ of the oxomolybdenum dithiolene fold angles observed to date are less than $\sim 20^{\circ}$, with the largest observed fold angle being $\sim 37^{\circ} .{ }^{42}$ (Figure 2) This stands in marked contrast to the observed $70^{\circ}$ fold angle observed here for $\mathrm{MoO}(\mathrm{SPh})_{2}\left(\mathrm{Pr}_{2} \mathrm{Dt}^{\circ}\right)$ (Figure 1). In 1976, Lauher and Hoffmann predicted that a large ligand folding would be possible for $\mathrm{d}^{2}$ metal centers (e.g. Ti(II), Mo(IV)) coordinated by neutral dithiolene (i.e. dithione) ligands. ${ }^{43}$ However, the observation of a large dithione ligand folding in the presence of a d ${ }^{2}$ metal center had not been realized until now in $\mathrm{MoO}(\mathrm{SPh})_{2}\left(\mathrm{iPr}_{2} \mathrm{Dt}^{\mathrm{o}}\right)$. Given the relatively small fold angles in oxomolybdenum dithiolenes that possess dominant dithiolene $\rightarrow \mathrm{Mo}\left(\mathrm{x}^{2}-\mathrm{y}^{2}\right) \mathrm{LMCT},{ }^{35},{ }^{42}$ the potential for very large fold angle distortions seems to be greater for dithione acceptor ligands in the presence of a $\mathrm{d}^{2}$ metal center, particularly when strong electron donating (e.g. thiolate) ligands are bound to the metal and oriented opposite the dithione acceptor ligand.

With respect to understanding the implications of the extremely large dithione ligand folding and fragment 1 (F1) HOMO $\rightarrow$ fragment 2 (F2) LUMO donor-acceptor interaction on the electronic structure of $\mathrm{MoO}(\mathrm{SPh})_{2}\left({ }^{\mathrm{i}} \mathrm{Pr}_{2} \mathrm{Dt}^{\mathrm{O}}\right)$, we have plotted the energies of the three $\mathrm{a}^{\prime}$ frontier molecular orbitals as a function of the fold angle $(\eta)$ in Figure 8. The effects of the ligand folding are dramatic and clearly point toward strong HOMO - LUMO orbital mixing in the electronic ground state. The symmetry of the closed shell ground state and the singlet excited state that derives from a HOMO $\rightarrow$ LUMO one electron promotion are both $\mathrm{A}^{\prime}$ in the $C_{S}$ symmetry of the complex. Thus, these states can mix by symmetry but may also be vibronically coupled via totally symmetric a' normal modes. The only source of the structural instability that can lead to dramatic fold angle distortions from the more planar reference, or high-symmetry, configuration of the nondegenerate $\mathrm{A}^{\prime}$ ground state is the $\mathrm{pJT}$ effect ${ }^{44,45}$. We adopt a modified two-state model to illustrate our point. Assuming that only the totally symmetric folding coordinate, $Q$, mixes the ground and excited states, the resulting state energies are given by:

$$
\left|\begin{array}{cc}
\Delta-V_{i i} Q-E & V_{i j} Q \\
V_{j i} Q & -\Delta+V_{i i} Q-E
\end{array}\right|=0
$$

where $2 \Delta$ is the energy gap between the states, $V_{i i}$ is the diagonal linear vibronic coupling constant, $Q$ is the folding coordinate, and $V_{i j}=V_{j i}$ is the off-diagonal linear vibronic coupling constant. The solutions, $E_{i}$ are given by,

$$
E^{v}= \pm \sqrt{\Delta^{2}-2 V_{i i} Q \Delta+V_{i i}^{2} Q^{2}+V_{i j}^{2} Q^{2}}
$$

This leads to adiabatic potential energy surfaces (APES) for the ground and excited states that are described by

$$
E_{ \pm}=\frac{1}{2} K_{0} Q^{2} \pm \sqrt{\Delta^{2}-2 V_{i i} Q \Delta+V_{i i}^{2} Q^{2}+V_{i j}^{2} Q^{2}}
$$


Where the force constant, $K_{0}$, is assumed to be the same in both the ground and excited states. The diagonal linear coupling terms, $V_{i i} Q$, describe the distorting forces in the ground and excited states along $Q$, but they do not mix these states. The vibronic interstate mixing is controlled by the magnitudes of $V_{i j}$ and $\Delta$, and a strong pJT effect is present when

$V_{i j}^{2} / K_{0}>\Delta$, leading to two minima on the lower APES. An example of the strong pJT effect where $V_{i i} \neq 0$ is given in Figure 9. Importantly, a non-zero value for $V_{i i} Q$ will result in different values for $Q$ in the ground and excited states (i.e. different fold angle distortions) and the two minima in the ground state APES possessing different energies. The reference configuration is defined as the point on the APES were $\mathrm{dV} / \mathrm{dQ}=0$ and $0>\mathrm{d}^{2} \mathrm{~V} / \mathrm{dQ}^{2}>0$. Although $\mathrm{d}^{2} \mathrm{~V} / \mathrm{dQ}^{2}$ may be either positive or negative, in the strong $p J$ T limit $\mathrm{d}^{2} \mathrm{~V} / \mathrm{dQ}^{2}<0$ at the reference configuration. This results in the appearance of a double potential well in the APES along the fold coordinate. For the equilibrium (minimum energy) geometry of the non-degenerate ground state, one has $\mathrm{dV} / \mathrm{dQ}=0$ and $\mathrm{d}^{2} \mathrm{~V} / \mathrm{dQ}^{2}>0$.

Figure 10 shows the results of a DFT scan of the ground state total energy as a function of the totally symmetric dithione ligand folding coordinate, and provides additional strong evidence for a strong pseudo Jahn-Teller (pJT) type distortion ${ }^{46}$ being operative of the ground state of $\mathrm{MoO}(\mathrm{SPh})_{2}\left(\mathrm{Pr}_{2} \mathrm{Dt}^{\mathrm{o}}\right)$. As predicted from Eqn (3), we observe a double minimum in the ground state potential energy surface (PES) (Figure 10) with a singular point of instability at a fold angle of $9^{\circ}$. Increased Mo-dithione orbital overlap in $\mathrm{MoO}(\mathrm{SPh})_{2}\left(\mathrm{Pr}_{2} \mathrm{Dt}^{\mathrm{o}}\right)$ results from this vibronically induced distortion along the totally symmetric bending coordinate. Thus, the bending of the dithione $\pi$ acceptor ligand drives an increase in Mo-dithione covalency, which results in a concomitant lowering of the total energy of the system. The strong pJT effect results in $\mathrm{MoO}(\mathrm{SPh})_{2}\left({ }^{\mathrm{i}} \mathrm{Pr}_{2} \mathrm{Dt}^{\mathrm{o}}\right)$ possessing ground state electronic bistability, with local and global minima along the fold coordinate. In marked contrast to the ground state APES, the excited state APES described by a HOMO $\rightarrow$ LUMO one-electron promotion is not subject to a strong pJT configurational instability and will possess markedly less pronounced ligand folding. We estimate an $\sim 20^{\circ}$ ligand fold angle in this singlet HOMO $\rightarrow$ LUMO excited state from the computed minimum geometry of the ${ }^{3} \mathrm{~A}^{\prime} \mathrm{LL} \mathrm{L}^{\prime} \mathrm{CT}$ excited state. The $\sim 10^{\circ}$ difference between the excited state minimum and the ground state reference configuration (point of instability in the ground state APES) and the $2.7 \mathrm{kcal} / \mathrm{mol}$ energy difference in the two minima of the ground state APES result from $V_{i i} \neq 0$.

\section{CONCLUSIONS}

The metallo-dithiolene complex $\mathrm{MoO}(\mathrm{SPh})_{2}\left({ }^{\mathrm{i}} \mathrm{Pr}_{2} \mathrm{Dt}^{\mathrm{O}}\right)$ has been synthesized and characterized by a combination of X-ray crystallography, electronic absorption spectroscopy, and resonance Raman spectroscopy and these data have been interpreted in the context of detailed bonding and spectroscopic calculations. The most striking feature of $\mathrm{MoO}(\mathrm{SPh})_{2}\left(\mathrm{Pr}_{2} \mathrm{Dt}^{\mathrm{o}}\right)$ is revealed by X-ray crystallography, which showed that the complex displayed an extremely large sulfur fold angle $\left(\eta=70^{\circ}\right)$ distortion with the dithione ligand folding up toward the terminal oxo. We have shown this ligand folding to derive from strong orbital mixing between occupied and virtual molecular orbitals of a' symmetry that possess mixed $\mathrm{Mo}\left(\mathrm{dx}^{2}-\mathrm{y}^{2}\right), \mathrm{PhS}^{-}$, and dithione orbital character. From a state prospective, the 
dramatic ligand folding is the result of a strong pJT effect with vibronic coupling between the $\mathrm{A}^{\prime}$ ground state and low-lying $\mathrm{A}^{\prime} \mathrm{LL}^{\prime} \mathrm{CT}$ excited states. The ligand folding distortion leads to an increase in the $\pi$ acceptor ability of the dithione and the onset of new covalency. The interstate vibronic coupling warps the ground state APES to create a bistable electronic ground state; a key electronic structure feature for molecular switching devices. Thus, the general electronic flexibility of metallodithiolenes has been fully exploited here to create a complex that displays unusual low-energy LL'CT transitions, and we have used these spectral features to directly probe the nature of the strong $\mathrm{SPh} \rightarrow$ dithione charge donation which stabilizes the pJT distorted ground state in $\mathrm{MoO}(\mathrm{SPh})_{2}\left({ }^{\mathrm{i}} \mathrm{Pr}_{2} \mathrm{Dt}^{\mathrm{o}}\right)$. Such strong $\mathrm{LL}^{\prime} \mathrm{CT}$ $\mathrm{D} \rightarrow$ A character is typically observed in planar mixed-ligand metallodithiolene complexes, ${ }^{4,},{ }^{14}, 18$ where the coplanar nature of the donor and acceptor ligands provided an ideal $\pi$ orbital pathway for strong $\mathrm{D} \rightarrow$ A charge transfer. We have shown here that this idea can be extended to non-planar systems when there exists a large acceptor ligand fold angle distortion that allows for in-plane orbitals of the donor to interact strongly with out-of-plane $\varphi_{\mathrm{op}}{ }^{\mathrm{a}}$ orbital on the acceptor ligand. The similarities between ligand/Mo $\left(\mathrm{dx}^{2}-\mathrm{y}^{2}\right) \rightarrow$ dithione and dithiolene $\rightarrow \mathrm{Mo}\left(\mathrm{dx}^{2}-\mathrm{y}^{2}\right)$ charge donation may result in fold angle distortions in oxomolybdenum complexes whether the Mo ion is in the $+4,+5$, or +6 oxidation state.

Dithiolene ligands are also found in biology as a vital component of the molybdenum cofactor (Moco), where the dithiolene chelate is part of a complex pyranopterin dithiolene ligand. ${ }^{47} 49$ When the dithiolene ligand is in the fully reduced 1,2-dithiolate form it functions as a good electron donor. Very recently it was shown that the pyranopterin dithiolene ligand in enzymes displays a range of non-planar distortions that could be associated with protein function. ${ }^{47}$ Furthermore, it was suggested that these non-planer distortions might arise from the different oxidation states of the pyranopterin dithiolene ligand. ${ }^{47}$ The pyranopterin dithiolene ligand found in Mo and $\mathrm{W}$ enzymes possesses a piperazine ring similar to that found in the ${ }^{i} \mathrm{Pr}_{2} \mathrm{Dt}^{\mathrm{o}}$ ligand of $\mathrm{MoO}(\mathrm{SPh})_{2}\left({ }^{\mathrm{i}} \mathrm{Pr}_{2} \mathrm{Dt}^{\mathrm{o}}\right)$. We have shown that these ring systems, in conjunction with the dithiolene, afford additional redox possibilities and these may play a role in the enzymes. ${ }^{20}, 31,32$ Interestingly, the Mo(IV)dithione/Mo(VI)-dithiolene couple constitute a valence tautomeric system. Thus, the determination of Mo and dithiolene oxidation states from molybdoenzyme protein crystallography may not straightforward if the pyranopterin dithiolene chelate in the enzymes can exist in different oxidation states.

\section{Supplementary Material}

Refer to Web version on PubMed Central for supplementary material.

\section{Acknowledgments}

M.L.K. and P.B. gratefully acknowledge support of this research by the National Institutes of Health (Grant No. GM-057378 to MLK and Grant No. GM-061555 to P.B.). MLK also acknowledges NSF CHE-1301142 for financial support.

\section{References}

1. Yang J, Kersi DK, Giles LJ, Stein BW, Feng CJ, Tichnell CR, Shultz DA, Kirk ML. Inorg Chem. 2014; 53:4791. [PubMed: 24773363] 
2. Bevilacqua JM, Eisenberg R. Inorg Chem. 1994; 33:2913.

3. Cummings SD, Eisenberg R. Inorg Chem. 1995; 34:2007.

4. Paw W, Cummings SD, Mansour MA, Connick WB, Geiger DK, Eisenberg R. Coord Chem Rev. 1998; 171:125.

5. Zuleta JA, Bevilacqua JM, Proserpio DM, Harvey PD, Eisenberg R. Inorg Chem. 1992; 31:2396.

6. Zuleta JA, Chesta CA, Eisenberg R. J Am Chem Soc. 1989; 111:8916.

7. Mogesa B, Perera E, Rhoda HM, Gibson JK, Oomens J, Berden G, van Stipdonk MJ, Nemykin VN, Basu P. Inorg Chem. 2015; 54:7703. [PubMed: 26244772]

8. Cummings SD, Eisenberg R. Progress in Inorganic Chemistry: Synthesis, Properties, and Applications. 2004; 52:315.

9. Kirk ML, McNaughton RL, Helton ME. Progress in Inorganic Chemistry: Synthesis, Properties, and Applications. 2004; 52:111.

10. Ray K, George SD, Solomon EI, Wieghardt K, Neese F. Chemistry-A European Journal. 2007; 13:2783.

11. Sproules S, Benedito FL, Bill E, Weyhermuller T, George SD, Wieghardt K. Inorg Chem. 2009; 48:10926. [PubMed: 19831363]

12. Sproules S, Wieghardt K. Coord Chem Rev. 2011; 255:837.

13. Eisenber R, Gray HB. Inorg Chem. 1967; 6:1844.

14. Deplano P, Pilia L, Espa D, Mercuri ML, Serpe A. Coord Chem Rev. 2010; 254:1434.

15. Bigoli F, Deplano P, Devillanova FA, Lippolis V, Lukes PJ, Mercuri ML, Pellinghelli MA, Trogu EF. Journal of the Chemical Society-Chemical Communications. 1995:371.

16. Bigoli F, Deplano P, Mercuri ML, Pellinghelli MA, Pintus G, Trogu EF, Zonnedda G, Wang HH, Williams JM. Inorg Chim Acta. 1998; 273:175.

17. Nemykin VN, Olsen JG, Perera E, Basu P. Inorg Chem. 2006; 45:3557. [PubMed: 16634586]

18. Frei F, Rondi A, Espa D, Mercuri ML, Pilia L, Serpe A, Odeh A, Van Mourik F, Chergui M, Feurer T, Deplano P, Vlcek A, Cannizzo A. Dalton Transactions. 2014; 43:17666. [PubMed: 25154705]

19. Espa D, Pilia L, Makedonas C, Marchiò L, Mercuri ML, Serpe A, Barsella A, Fort A, Mitsopoulou CA, Deplano P. Inorg Chem. 2014; 53:1170. [PubMed: 24405208]

20. Mtei RP, Perera E, Mogesa B, Stein B, Basu P, Kirk ML. European Journal of Inorganic Chemistry. 2011:5467. [PubMed: 23956683]

21. Pratt CS, Coyle BA, Ibers JA. Journal of the Chemical Society a -Inorganic Physical Theoretical. 1971:2146.

22. Gaussian 03. R. C. G., Inc.; Pittsburgh, PA: 2003.

23. Molecular orbitals were analyzed using the AOMix program [a, b](a) Gorelsky, SI. AOMix: Program for Molecular Orbital Analysis. York University; Toronto: 1997. http://www.sg-chem.net/ aomix/(b) Gorelsky SI, Lever ABP. J Organomet Chem. 2001; 635:187-196.

24. Millar AJ, Doonan CJ, Smith PD, Nemykin VN, Basu P, Young CG. Chemistry-A European Journal. 2005; 11:3255.

25. McNaughton RL, Tipton AA, Rubie ND, Conry RR, Kirk ML. Inorg Chem. 2000; 39:5697. [PubMed: 11151370]

26. Perera E, Basu P. Dalton Transactions. 2009:5023. [PubMed: 19662295]

27. Basu P, Nemykin VN, Sengar RS. Inorg Chem. 2009; 48:6303. [PubMed: 19485389]

28. Sengar RS, Nemykin VN, Basu P. J Inorg Biochem. 2008; 102:748. [PubMed: 18187198]

29. McNaughton RL, Helton ME, Cosper MM, Enemark JH, Kirk ML. Inorg Chem. 2004; 43:1625. [PubMed: 14989655]

30. McNaughton RL, Mondal S, Nemykin VN, Basu P, Kirk ML. Inorg Chem. 2005; 44:8216. [PubMed: 16270958]

31. Matz KG, Mtei RP, Rothstein R, Kirk ML, Burgmayer SJN. Inorg Chem. 2011; 50:9804. [PubMed: 21894968]

32. Matz KG, Mtei RP, Leung B, Burgmayer SJN, Kirk ML. J Am Chem Soc. 2010; 132:7830. [PubMed: 20481628] 
33. Donahue JP, Holm RH. Acta Crystallographica Section C-Crystal Structure Communications. 1998; 54:1175.

34. Inscore F, McNaughton R, Westcott B, Helton M, Jones R, Dhawan I, Enemark J, Kirk M. Inorg Chem. 1999; 38:1401.

35. Inscore FE, Knottenbelt SZ, Rubie ND, Joshi HK, Kirk ML, Enemark JH. Inorg Chem. 2006; 45:967. [PubMed: 16441102]

36. Inscore FE, McNaughton R, Westcott BL, Helton ME, Jones R, Dhawan IK, Enemark JH, Kirk ML. Inorg Chem. 1999; 38:1401.

37. Burgmayer SJN, Kim M, Petit R, Rothkopf A, Kim A, BelHamdounia S, Hou Y, Somogyi A, Habel-Rodriguez D, Williams A, Kirk ML. J Inorg Biochem. 2007; 101:1601. [PubMed: 17765313]

38. Drew SC, Hanson GR. Inorg Chem. 2009; 48:2224. [PubMed: 19235982]

39. Joshi HK, Cooney JJA, Inscore FE, Gruhn NE, Lichtenberger DL, Enemark JH. Proc Natl Acad Sci U S A. 2003; 100:3719. [PubMed: 12655066]

40. Joshi HK, Enemark JH. J Am Chem Soc. 2004; 126:11784. [PubMed: 15382900]

41. Wiebelhaus NJ, Cranswick MA, Klein EL, Lockett LT, Lichtenberger DL, Enemark JH. Inorg Chem. 2011; 50:11021. [PubMed: 21988484]

42. Donahue JP, Goldsmith CR, Nadiminti U, Holm RH. J Am Chem Soc. 1998; 120:12869.

43. Lauher JW, Hoffmann R. J Am Chem Soc. 1976; 98:1729.

44. Gorinchoy NN, Balan II, Bersuker IB. Computational and Theoretical Chemistry. 2011; 976:113.

45. Bersuker, IB. Electronic Structure and Properties of Transition Metal Compounds: Introduction to the Theory. Wiley; Hoboken, NJ: 2010.

46. Bersuker IB. Chemical Reviews. 2013; 113:1351. [PubMed: 23301718]

47. Rothery RA, Stein B, Solomonson M, Kirk ML, Weiner JH. Proc Natl Acad Sci U S A. 2012; 109:14773. [PubMed: 22927383]

48. Kirk, ML.; Stein, B. Comprehensive Inorganic Chemistry II. Second. Jan, R.; Kenneth, P., editors. Elsevier; Amsterdam: 2013. p. 263

49. Hille R, Hall J, Basu P. Chemical Reviews. 2014; 114:3963. [PubMed: 24467397] 

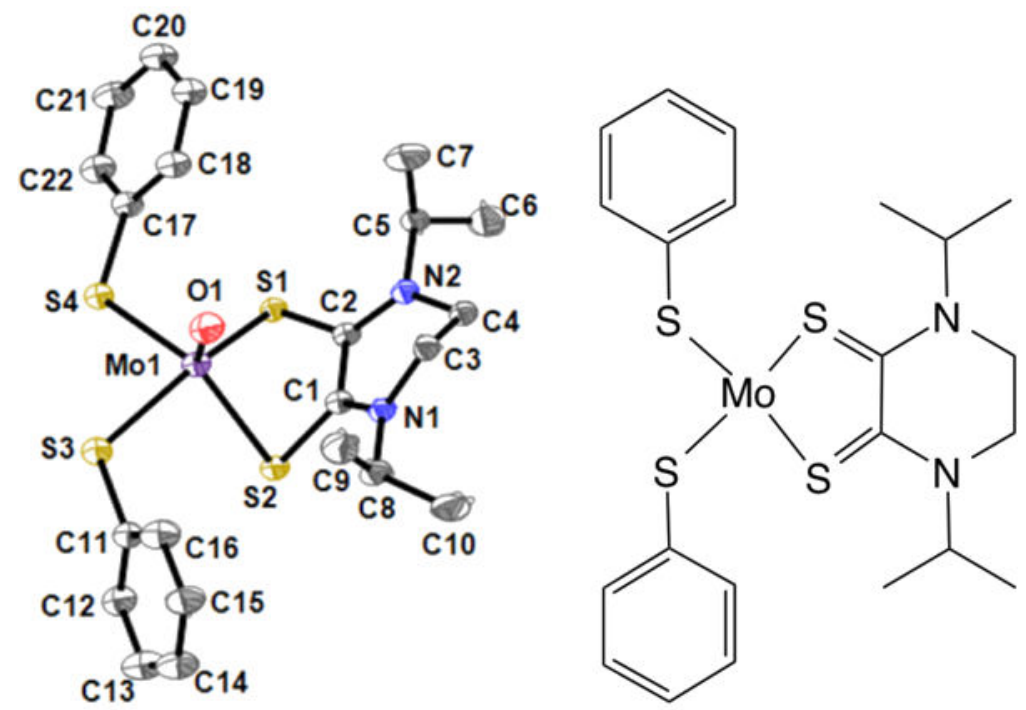

Figure 1.

Thermal ellipsoid plot (30\%) (Left) and corresponding bond line drawing (right) for $\mathrm{MoO}(\mathrm{SPh})_{2}\left({ }^{\mathrm{i}} \operatorname{Pr} 2 \mathrm{Dt}^{\mathrm{O}}\right)$ 


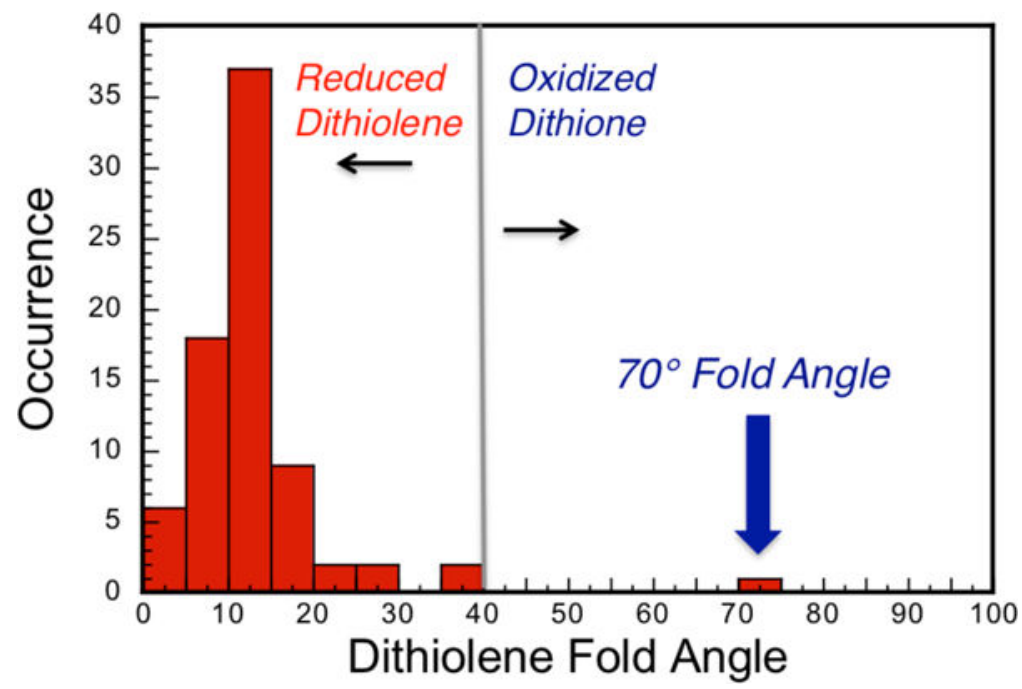

Figure 2.

A histogram of the oxomolybdenum dithiolene fold angles determined by X-ray crystallography. A listing of the fold angles associated with this histogram can be found in Table S3 of the SI. The most common dithiolene fold angle is $\sim 12.5^{\circ}$ and the largest is $\sim 37^{\circ}$. Note that the $70^{\circ}$ dithione fold angle in $\mathrm{MoO}(\mathrm{SPh})_{2}\left({ }^{\mathrm{i}} \mathrm{Pr}_{2} \mathrm{Dt}^{\mathrm{o}}\right)$ represents an extreme deviation from the observed fold angles for reduced dithiolene ligands. 

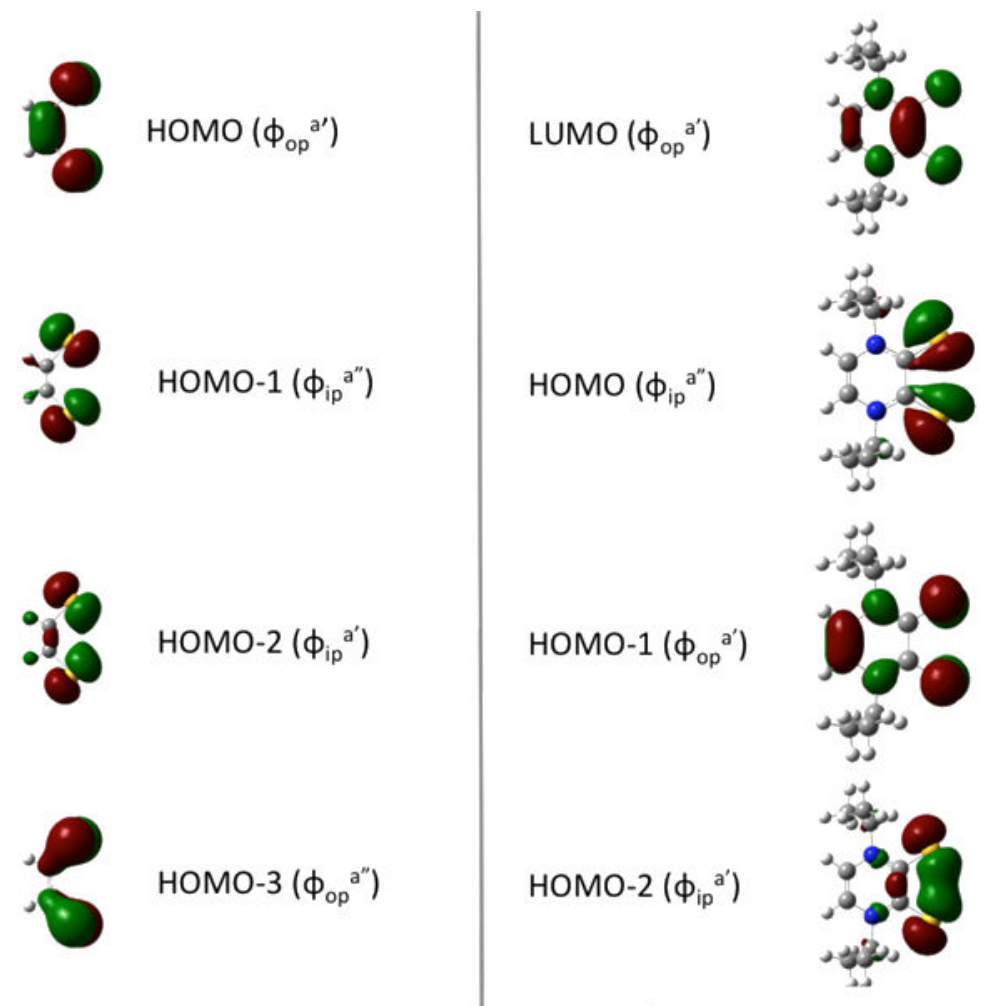

Figure 3.

Comparison of dithiolene and ${ }^{i} \mathrm{Pr}_{2} \mathrm{Dt}^{\mathrm{o}}$ dithione frontier MOs. Left: The four HOMOs for the dianionic dithiolene $\left(\mathrm{C}_{2} \mathrm{H}_{2} \mathrm{~S}_{2}\right)^{2-}$. Two-electron oxidation can yield the dithione form of the ligand if electrons are removed from the dithiolene HOMO, and the dithiete form of the ligand if electrons are removed from the HOMO-1 orbital. Right: Corresponding MOs for the ${ }^{\mathrm{i}} \mathrm{Pr}_{2} \mathrm{Dt}^{\mathrm{o}}$ ligand. 

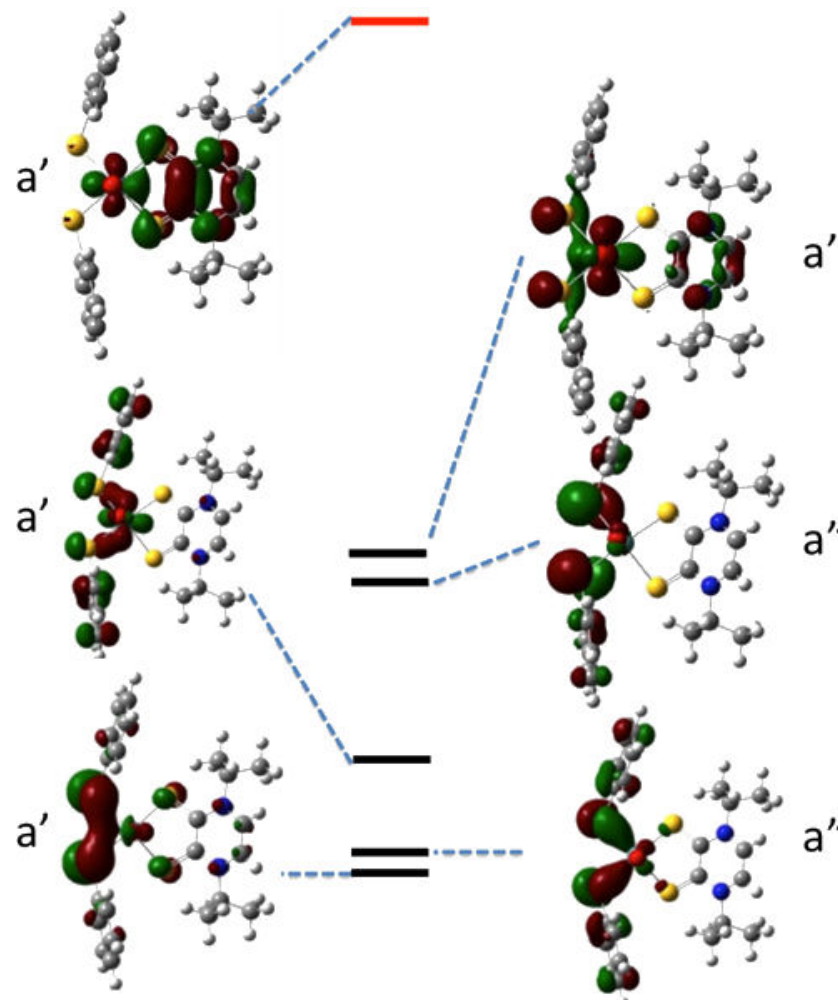

Figure 4.

Valence molecular orbital diagram for $\mathrm{MoO}(\mathrm{SPh})_{2}\left(\mathrm{Pr}_{2} \mathrm{Dt}^{\mathrm{O}}\right)$ in idealized $C_{S}$ symmetry. Filled MOs are denoted in black and the virtual LUMO is depicted in red. Relative energy spacings are qualitative. 


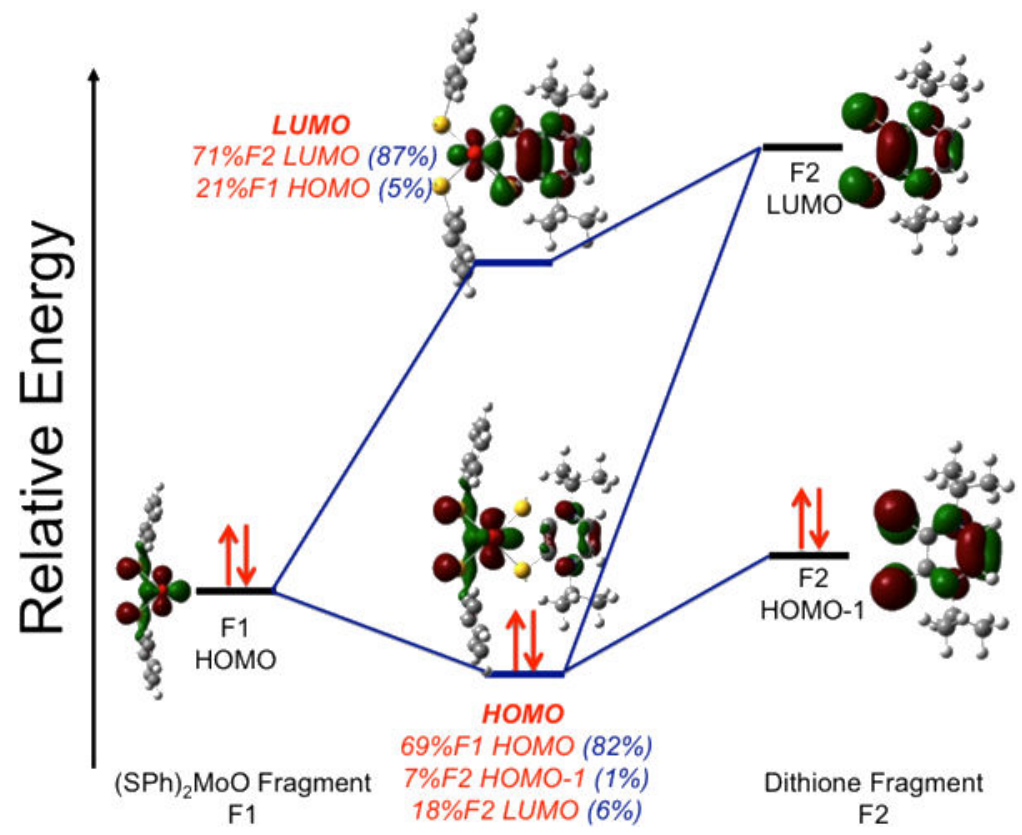

Figure 5.

Fragment molecular orbital diagram for $\mathrm{MoO}(\mathrm{SPh})_{2}\left(\mathrm{Cr}_{2} \mathrm{Dt}^{\mathrm{O}}\right)$ in idealized $C_{S}$ symmetry. With respect to the $\mathrm{MoO}(\mathrm{SPh})_{2}\left(\mathrm{i}_{2} \mathrm{Pt}^{\mathrm{O}}\right) \mathrm{HOMO}$, the dithione (F2) LUMO possesses dominant $\pi$ acceptor character. The F1 and F2 fragment MO contributions to the HOMO and LUMO are given in red. In the absence of any dithione ligand folding (blue) the dithione acceptor character is reduced by $2 / 3$. 


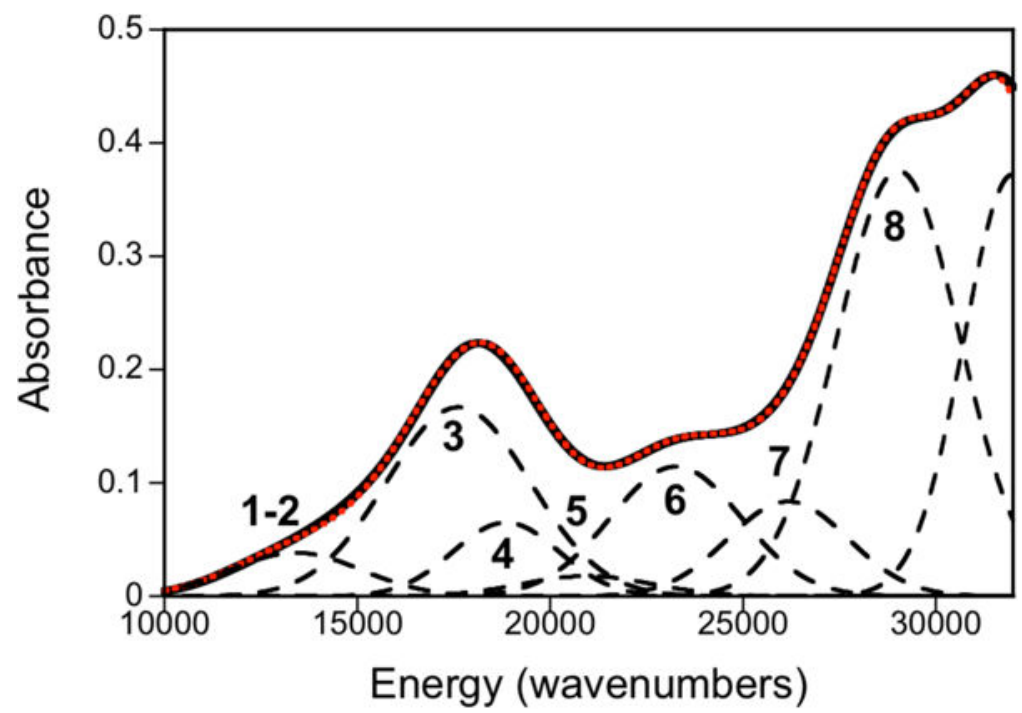

Figure 6.

Gaussian resolved room temperature electronic absorption spectrum of $\mathrm{MoO}(\mathrm{SPh})_{2}\left({ }^{\mathrm{i}} \mathrm{Pr}_{2} \mathrm{Dt}^{\mathrm{o}}\right)$ in acetonitrile. 


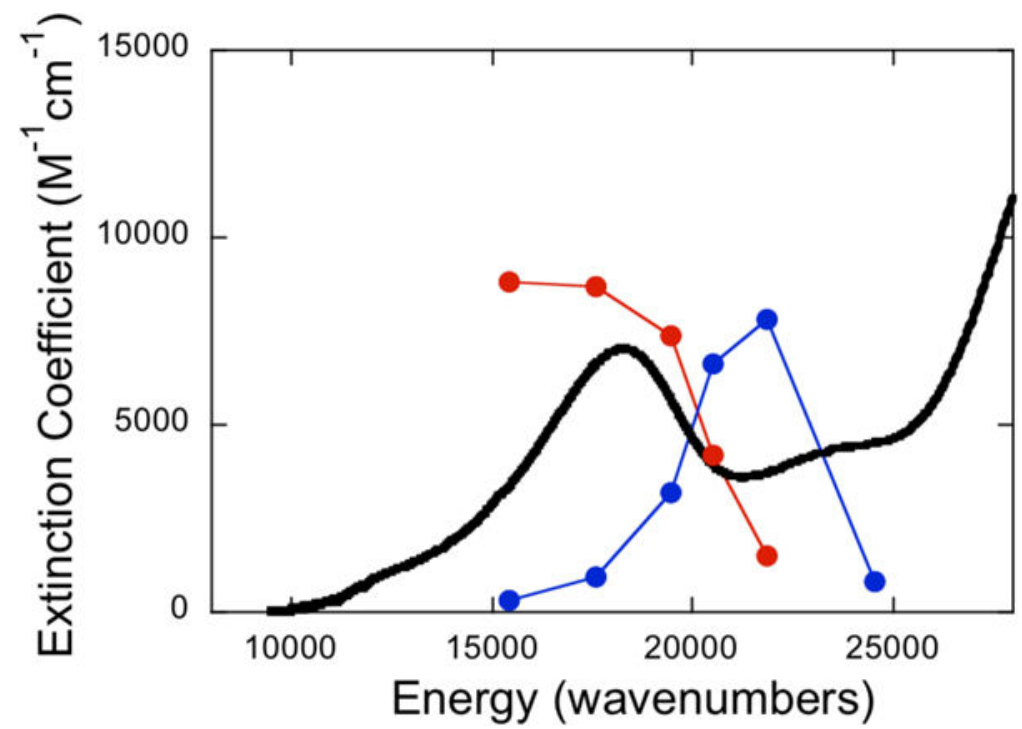

Figure 7.

Resonance Raman profiles for the $378 \mathrm{~cm}^{-1} \mathrm{~S}-\mathrm{Mo}-\mathrm{S}$ stretch (dithione) + ring C-N stretch (dithione) mode, (red circles) and the $945 \mathrm{~cm}^{-1} \mathrm{Mo} \equiv \mathrm{O}$ stretch (blue circles). The resonance enhancement patterns indicate that $\mathrm{CT}$ transitions to the $\mathrm{Mo} \equiv \mathrm{O}$ d-p $\pi^{*}$ orbitals occur at higher energy than $\mathrm{LL}^{\prime} \mathrm{CT}$ transitions to the ${ }^{\mathrm{i}} \mathrm{Pr}_{2} \mathrm{Dt}^{\mathrm{o}}$ ligand LUMO. 


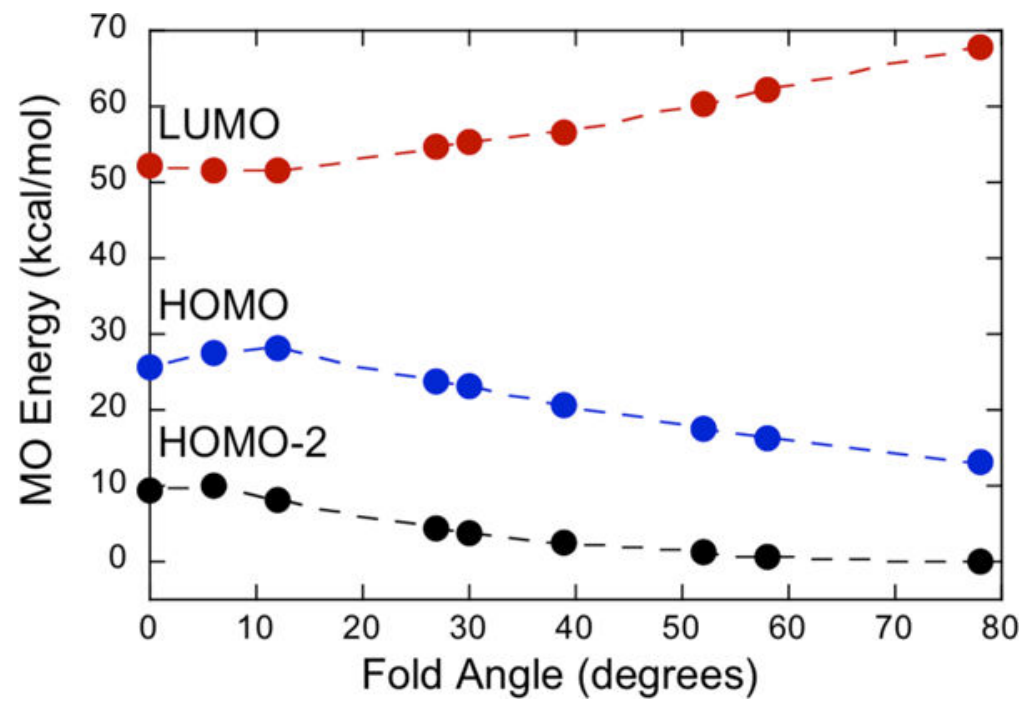

Figure 8.

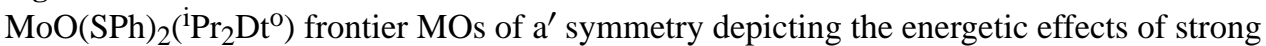
orbital mixing as a function of the dithione S-S fold angle. 


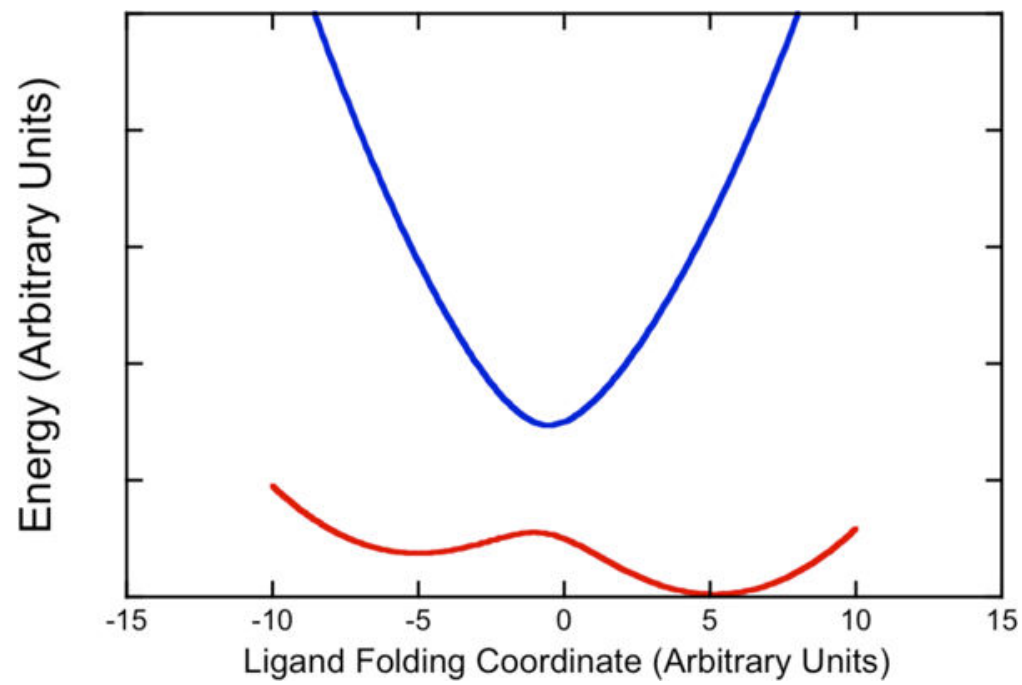

Figure 9.

APES in the limit of a strong pJT effect in the two-state approximation according to Eqn. 3. 


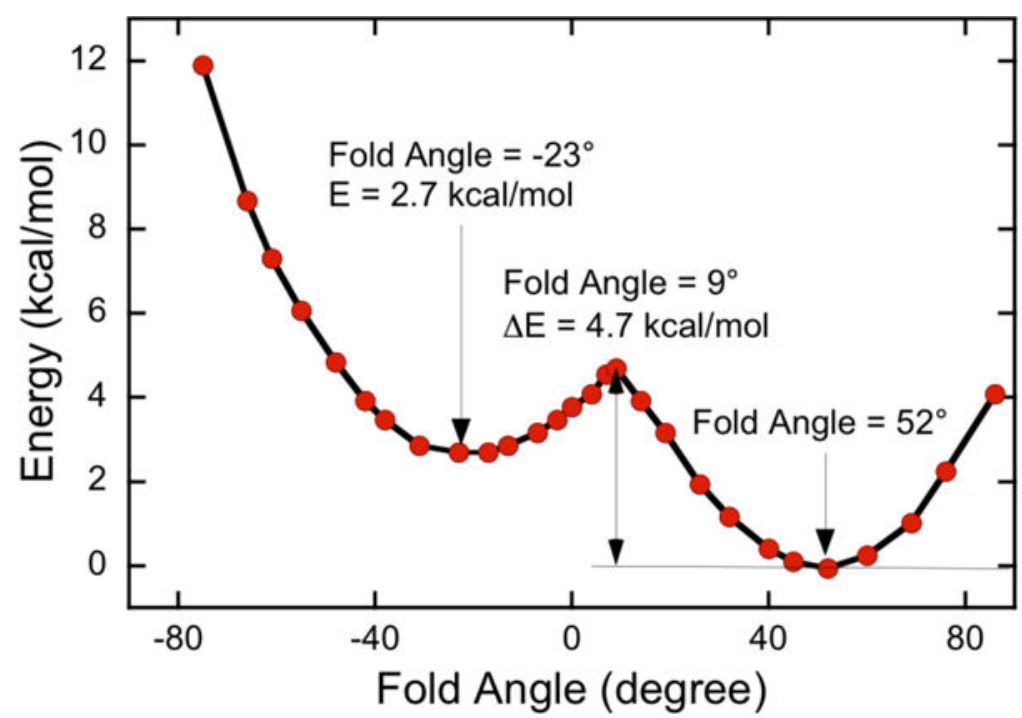

Figure 10.

Total energy as a function of the dithione S-S fold angle. The observation of double minimum in the ground state potential energy surface indicates the presence of a strong $\mathrm{pJT}$ distortion that results from vibronic mixing between the ground state and at least one additional excited state of the same symmetry. 
ene-1,2-dithiolate radical anion 1,2-dithione 1,2-dithiete

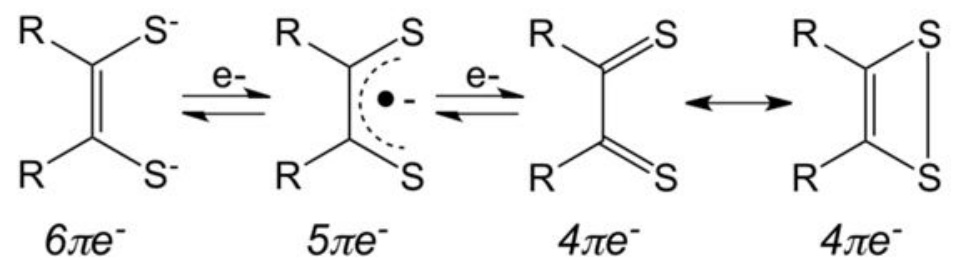

Scheme 1.

Dithiolene ligand forms. 


\section{Table 1}

Selected vibrational modes

\begin{tabular}{|c|c|c|c|}
\hline Modes & Freq (exp) & Freq (calc) & Assignment $^{a}$ \\
\hline$v_{25}$ & 237 & 235 & Mo-oxo wag \\
\hline$v_{31}$ & 286 & 288 & $\begin{aligned} & \text { Mo-oxo wag } \\
+ & \text { C-S-S-C bend }\end{aligned}$ \\
\hline$v_{35} / v_{36}$ & 362 & $349 / 356$ & S-Mo-S stretch (dithione)/S-Mo-S stretch (thiolate) +ring folding \\
\hline$v_{37}$ & 378 & 384 & S-Mo-S stretch (dithione) + ring C-N stretch (dithione)+ring folding \\
\hline$v_{81}$ & 945 & 996 & $\mathrm{Mo} \equiv \mathrm{O}$ stretch \\
\hline
\end{tabular}

${ }^{a}$ Totally symmetric vibrational modes in idealized $C_{S}$ symmetry. 
Table 2

Electronic absorption band assignments based on DFT computations and resonance Raman profiles.

\begin{tabular}{ccc}
\hline Band & Energy (exp) & Assignment \\
\hline 1 & 12,900 & $\mathrm{SPh} \rightarrow \mathrm{L}^{\prime}(\mathrm{LUMO})$ \\
2 & 12,900 & $\mathrm{SPh} \rightarrow \mathrm{L}^{\prime}(\mathrm{LUMO})$ \\
3 & 17,500 & $\mathrm{SPh} \rightarrow \mathrm{L}^{\prime}(\mathrm{LUMO})$ \\
4 & 18,800 & $\mathrm{SPh} \rightarrow \mathrm{L}^{\prime}(\mathrm{LUMO})$ \\
5 & 20,800 & $\mathrm{Mo}\left(\mathrm{x}^{2}-\mathrm{y}^{2}\right) \rightarrow \mathrm{L}^{\prime}(\mathrm{LUMO})$ \\
6 & 23,300 & $\mathrm{SPh} \rightarrow \mathrm{Mo}(\mathrm{xz})$ \\
7 & 26,100 & $\mathrm{SPh} \rightarrow \mathrm{Mo}(\mathrm{yz})$ \\
8 & 29,000 & $\mathrm{SPh} \rightarrow \mathrm{Mo}(\mathrm{xz})$ \\
\hline
\end{tabular}

ᄅ

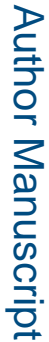

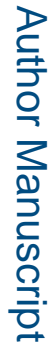

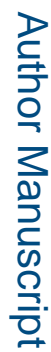

Inorg Chem. Author manuscript; available in PMC 2017 January 19. 